\title{
Direct Marketing, Indirect Profits: A Strategic Analysis of Dual-Channel Supply-Chain Design
}

\author{
Wei-yu Kevin Chiang • Dilip Chhajed • James D. Hess \\ Department of Information Systems, University of Maryland at Baltimore County, Baltimore, Maryland 21250 \\ Department of Business Administration, University of Illinois at Urbana-Champaign, Champaign, Illinois 61820 \\ Department of Business Administration, University of Illinois at Urbana-Champaign, Champaign, Illinois 61820 \\ kevin@wchiang.net•chhajed@uiuc.edu・ jhess@uiuc.edu
}

\begin{abstract}
$\mathrm{T}$ he advent of e-commerce has prompted many manufacturers to redesign their traditional channel structures by engaging in direct sales. The model conceptualizes the impact of customer acceptance of a direct channel, the degree to which customers accept a direct channel as a substitute for shopping at a traditional store, on supply-chain design. The customer acceptance of a direct channel can be strong enough that an independent manufacturer would open a direct channel to compete with its own retailers. Here, direct marketing is used for strategic channel control purposes even though it is inefficient on its own and, surprisingly, it can profit the manufacturer even when no direct sales occur. Specifically, we construct a pricesetting game between a manufacturer and its independent retailer. Direct marketing, which indirectly increases the flow of profits through the retail channel, helps the manufacturer improve overall profitability by reducing the degree of inefficient price double marginalization. While operated by the manufacturer to constrain the retailer's pricing behavior, the direct channel may not always be detrimental to the retailer because it will be accompanied by a wholesale price reduction. This combination of manufacturer pull and push can benefit the retailer in equilibrium. Finally, we show that the mere threat of introducing the direct channel can increase the manufacturer's negotiated share of cooperative profits even if price efficiency is obtained by using other business practices.

(Supply Chain Management; Channels of Distribution; Internet/Direct Marketing; e-Commerce; Competitive Strategy; Game Theory)
\end{abstract}

\section{Introduction}

The rapid development of commerce on the Internet has made it easier for many manufacturers who traditionally distribute their products through retailers to engage in direct sales. According to one survey reported in The New York Times (Tedeschi 2000), about $42 \%$ of top suppliers (e.g., IBM, Pioneer Electronics, Cisco System, Estee Lauder, and Nike) in a variety of industries have begun to sell directly to consumers over the Internet. While more and more manufacturers are engaging in direct sales, their retailer partners voice the belief that orders placed through a manufacturer's direct channel are orders that should have been placed through them.

To avoid this "channel conflict," some manufacturers (e.g., Levi Strauss \& Co.) have halted direct sales (Collett 1999), while others have tried to convince retailers that their direct channel taps customer segments that would otherwise not buy.

Herman Miller Inc., Zeeland, Mich., which manufactures office furniture, is careful to explain to its dealers that its online efforts are targeting the home office 
market, a segment that its dealer network wasn't serving. (Keenan 1999, p. 18)

Whether retailers are convinced or not, direct sales typically are modest at best. In 1999, the conventional bricks-and-mortar stores rang up 93\% of United States retail sales revenue; e-commerce, by contrast, accounted for about $1 \%$, and catalog sales the other $6 \%$ (Collett 1999). Many times direct marketing is used just to provide information and to support sales in traditional channels. Companies, such as Xerox, use the web and direct mail to generate leads for their product lines.

\begin{abstract}
"More and more customers are coming to the Web to learn about products before they go to a retail store," says Anne Mulcahy, president of Xerox General Markets Operations (GMO). A major focus for GMO is convincing account salespeople to represent Xerox's total solution-even though some of those products, such as printers, are typically fulfilled through an indirect channel. (Cohen 2000, p. 13)
\end{abstract}

Why would a manufacturer add a direct channel, possibly alienating its traditional retailers, when the direct channel is unlikely to produce sales? Our theory suggests that rather than fearing channel conflict, as the trade press suggests, manufacturers may want "go direct" in part to motivate retailers to perform more effectively from the manufacturer's perspective.
Moreover, retailers should not be too quick to judge the manufacturer's direct marketing as injurious, even if it appears to cannibalize their sales. A complete analysis of the strategic decision of the manufacturer suggests that the introduction of the direct channel will be accompanied by a wholesale price reduction. This combination of manufacturer pull and push can actually benefit the retailer in equilibrium.

\subsection{Preview of Our Results}

To demonstrate this strategic mission of direct marketing as a channel control device, consider the numerical illustration in Table 1 (constructed using the theoretical model developed below). If the channel was an integrated unit, the retail price would be low (\$7.50) with a low unit profit margin (\$2.50) but with high sales $(25,000$ units). If the retailer is independent, both the manufacturer and retailer try to earn substantial profit margins $(\$ 2.50=\$ 7.50-\$ 5.00$ and $\$ 1.25=\$ 8.75-\$ 7.50$, respectively). The consequence is that unit sales are only $50 \%$ of the ideal, and the independent channel as a whole loses $25 \%$ of its profit potential due to poor price coordination.

Now consider what happens when the manufacturer introduces a direct market in a dual-channel strategy. The direct price undercuts the retailer, but the wholesale price is simultaneously reduced (from

Table 1 Illustration of the Channel Control Benefits of Direct Marketing

\begin{tabular}{|c|c|c|c|c|}
\hline Variables & $\begin{array}{l}\text { Integrated } \\
\text { manufacturer- } \\
\text { retailer }\end{array}$ & $\begin{array}{l}\text { Independent } \\
\text { retail channel }\end{array}$ & $\begin{array}{c}\text { Dual channel } \\
\text { (independent retailer } \\
+ \text { direct) }\end{array}$ & $\begin{array}{l}\text { Difference due to } \\
\text { direct marketing } \\
\text { threat }\end{array}$ \\
\hline \multicolumn{5}{|l|}{ Price: } \\
\hline Wholesale & - & $\$ 7.50$ & $\$ 6.67$ & $-11 \%$ \\
\hline Retail store & $\$ 7.50$ & $\$ 8.75$ & $\$ 8.00$ & $-9 \%$ \\
\hline Direct channel & - & - & $\$ 6.67$ & - \\
\hline \multicolumn{5}{|l|}{ Sales: } \\
\hline Retail store & 25,000 & 12,500 & 20,000 & $+60 \%$ \\
\hline Direct channel & - & - & 0 & $+0 \%$ \\
\hline \multicolumn{5}{|l|}{ Profit: } \\
\hline Manufacturer* & - & $\$ 31,250$ & $\$ 33,400$ & $+7 \%$ \\
\hline Retailer & - & $\$ 15,625$ & $\$ 26,600$ & $+70 \%$ \\
\hline Total & $\$ 62,500$ & $\$ 46,875$ & $\$ 60.000$ & $+28 \%$ \\
\hline
\end{tabular}


$\$ 7.50$ to $\$ 6.67)$. The best response of the retailer is to drop the retail price from $\$ 8.75$ to $\$ 8.00$ as seen in Table 1. The retailer's price reduction protects it perfectly from cannibalization by the direct market (zero sales occur in the direct channel), and increases its sales volume (from 12,500 to 20,000 units), its profit margin (from $\$ 1.25$ to $\$ 1.33$ ), and total profits (by $70 \%$ ).

One might expect that the manufacturer is hurt when it sets up a direct channel that cannot sell anything. Surprisingly, that is not true. The direct channel adds profits indirectly. The threat to sell in the direct channel induces greater sales in the traditional retail channel (by 60\%), and this more than makes up for the lower unit profit margins (33\% lower). The manufacturer's profits grow by $7 \%$ even though nothing is sold in its direct channel.

Our channel control explanation of dual-channel strategy also appears in Dutta et al.'s (1995) empirical study of dual-personal sales organizations, where incumbent independent sales representatives who believe they are irreplaceable may try to "holdup" the manufacturer for better commissions. Dutta et al. (1995) argue that manufacturers protect themselves from this threat by having their own house account sales force that could substitute for the independent sales representative. This transaction cost analysis focuses on the division of a fixed channel profit "pie" between manufacturer and distributor. We address this subdivision issue in $\S 5$, but the primary principle established here focuses on expanding the channel profit "pie." Specifically, if the existing downstream channel member has monopoly power, it exploits its power by enlarging per unit profit margins at the expense of dramatically shrinking the sales volume and thus the channel profits. Under some conditions, the manufacturer adds a dual channel, not to get a larger share of the channel profit, but rather to induce the existing channel to expand sales volume and profits to a more efficient level.

\subsection{Literature Review}

Previous work on dual channels has focused on franchising and personal selling, rather than direct marketing. The explanations of dual channels in the franchising/personal selling domains are not completely applicable to joining direct channels with preexisting retail channels. Specifically,

(1) Caves and Murphy (1976) argued that the manufacturer runs out of capital funds to finance company-owned outlets, and so begins franchising. However, the capital constraint theory implies that company-owned channels would predate independent retail channels, which is not typically the case for direct channels.

(2) Monitoring costs of company-owned outlets rise with physical distance from headquarters, so beyond some distance, it is better to have franchisees (Rubin 1978). However, physical distance is meaningless with respect to Internet sites or catalogs.

(3) Franchisees have information-gathering advantages about demand, but company outlets have lower fixed costs, so a mixture of the two is optimal (Minkler 1991). However, traditional retailers carry a large number of brands in each category, so it is not obvious that fixed costs per brand are higher for retailers than for a company-owned direct channel.

(4) Company outlets credibly signal profitability of the manufacturer's brand to potential franchisees (Gallini and Lutz 1992). However, for a mature brand there is no need to signal profitability to retailers who have successfully sold the brand for years.

(5) Comparison with the company's own salespeople decreases uncertainty about performance, reducing transactions costs with independent sales representatives (Dutta et al. 1995). However, we are primarily interested in goods that do not involve a large pre- and postsale service, so performance measures of the retailer are not an issue.

(6) Finally, dual channels may reach potential buyer segments that could not be reached by a single channel (Moriarty and Moran 1990). This is clearly true for Internet and catalog direct marketing. Our theory of channel control does not depend on the presence of a segment, and should be thought of as a complement to this justification of dual channels.

Of course, the channel coordination problem between manufacturer and retailer has been intensely studied by other theorists addressing strategic solutions other than direct channels. Jeuland and Shugan (1983), for example, show that quantity discounts 
can achieve coordination in such a system. McGuire and Staelin (1983) consider the partial substitutability between two products from two manufacturers each selling through exclusive retailers. They conclude that selling through resellers is preferable in highly competitive markets, and company-owned stores are better otherwise. Ingene and Parry (1995) study the case of a manufacturer that sells to independent retailers that directly compete for customers. They show that coordination is not always in the manufacturer's interest when retailers compete. Desiraju and Moorthy (1997) consider the channel management problem in a setting where information held by manufacturers and retailers about demand conditions are asymmetric. They argue that performance requirements on both price and service will improve channel performance. Gerstner and Hess (1995) show that manufacturers can enhance channel price coordination by designing pull-price discounts that target price-conscious consumers. The increased price coordination improves total channel profits and consumer surplus. Creating competition via direct channels supplements all of the above strategies.

The study of direct versus retail competition began only recently. Balasubramanian (1998) models competition in the multiple-channel environment from a strategic viewpoint. The level of information disseminated by the direct marketer is shown to have strategic implications, and he analyzes the use of market coverage as a lever to control competition. Tsay and Agrawal (2001) extend the literature on supplychain coordination to the setting where the upstream party is at once a supplier to and a competitor of the downstream party. They examine ways to adjust the manufacturer-reseller relationships that have been observed in industry. Rhee and Park (1999) present the hybrid channel design problem by modeling the interaction between a manufacturer and a retailer under the assumption of two consumer segments: a price-sensitive segment and a service-sensitive segment. They show that the hybrid channel is optimal when the segments are similar in their valuations of the retail service.

This paper extends the literature related to the manufacturers' dual-channel supply-chain design problems by addressing the following research questions.
How does the addition of a direct channel to a conventional retail channel affect the pricing strategies, the sales, and the profits of a vertically integrated firm? What is the impact of customer channel preference on the dual-channel problems? We analyze the incentives for a manufacturer to create its own direct channel to compete with its retailer, and conclude that direct marketing can help the manufacturer solely by increasing the profits earned by sales through its retailer.

\section{Notation and the Traditional Channel Model}

In this section, we introduce notation, the basic model of consumer choice, and the channel pricing decisions when a product is sold only in a traditional bricks-and-mortar retail store (henceforth, we will call this a retailer for brevity). The interactions between the manufacturer and retailer are modeled using the familiar Stackelberg game theory.

Assume that consumers are heterogeneous in the valuation of the product. We denote the consumption value (alternatively called "willingness to pay") by $v$, and for analytic simplicity, assume that it is uniformly distributed within the consumer population from 0 to 1 , with a density of 1 (see Figure 1).

The retailer offers the product at price $p_{r}$, so a consumer with valuation $v$ would derive a net consumer surplus of $v-p_{r}$ by buying the product. We assume, in this section, that the product is not available for sale elsewhere, so all consumers whose valuations satisfy $v-p_{r} \geq 0$ will buy. Specifically, the consumer whose valuation equals $p_{r}$ is indifferent to buying from the retailer or not, and all consumers with valuations in the interval $\left[p_{r}, 1\right]$ buy the product. In summary,

Figure 1 Distribution of Consumption Value

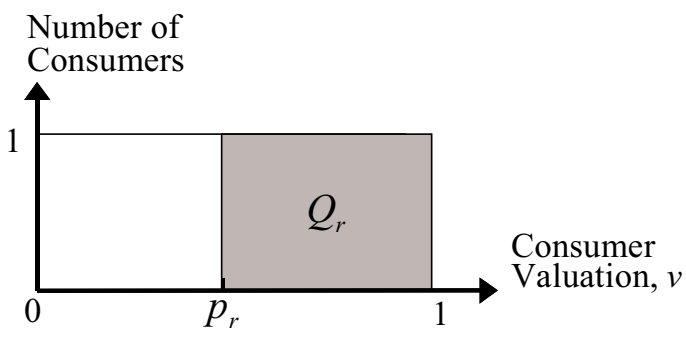

Management Science/Vol. 49, No. 1, January 2003 
consumer demand for the product at the traditional retailer is $Q_{r}=1-p_{r}$, for $0 \leq p_{r} \leq 1$ (see Figure 1).

The monopolist manufacturer supplies the exclusive retailer at a wholesale price, $w$, and incurs a cost per unit, $c_{r}$, that includes the cost of manufacturing and logistics. ${ }^{1}$ For analytic simplicity, assume that the retailer has no merchandising costs associated with the product. As a result, in the independent channel, the retailer's profits are determined by

$$
\pi_{r}=\left(p_{r}-w\right) Q_{r}=\left(p_{r}-w\right)\left(1-p_{r}\right),
$$

and the manufacturer's profits are determined by

$$
\pi_{m}=\left(w-c_{r}\right) Q_{r}=\left(w-c_{r}\right)\left(1-p_{r}\right) .
$$

If the two firms were vertically integrated, the profit of the integrated firm would be

$$
\pi_{v i}=\left(p_{r}-c_{r}\right) Q_{r}=\left(p_{r}-c_{r}\right)\left(1-p_{r}\right) .
$$

If the manufacturer acts as a Stackelberg price leader in an independent channel, then the manufacturer sets the wholesale price before the retailer chooses the retail price. The retailer takes the wholesale price as predetermined and maximizes retail profits given in Equation (1) with respect to retail price. The manufacturer anticipates this retail response and maximizes manufacturer profits given in Equation (2) subject to the retail pricing decision. ${ }^{2}$ Each firm does the best that it can, but they independently seek high-profit margins, and as a result, the price is higher and sales volume and profits are lower than that of a vertically integrated channel. ${ }^{3}$ This is the well-known "double marginalization" result of Spengler (1950).

Many remedies for the double-marginalization problem have been analyzed during the years, includ-

\footnotetext{
${ }^{1}$ Later in the paper, $c_{d}$ will correspond to manufacturer costs when distributing through the direct channel.

${ }^{2}$ The Stackelberg-Nash equilibrium with independent channel members is $w^{\text {indep }}=\left(1+c_{r}\right) / 2, p_{r}^{\text {indep }}=\left(3+c_{r}\right) / 4, Q_{r}^{\text {indep }}=\left(1-c_{r}\right) / 4$, $\pi_{m}^{\text {indep }}=\left(1-c_{r}\right)^{2} / 8$, and $\pi_{r}^{\text {indep }}=\left(1-c_{r}\right)^{2} / 16$.

${ }^{3}$ Specifically, $p_{r}^{v i}=\left(1+c_{r}\right) / 2, Q_{r}^{v i}=\left(1-c_{r}\right) / 2$, and $\pi^{v i}=\left(1-c_{r}\right)^{2} / 4$. Clearly, $p_{r}^{\text {indep }}>p_{r}^{v i}, Q_{r}^{\text {indep }}<Q_{r}^{v i}$, and $\pi_{r}^{\text {indep }}+\pi_{m}^{\text {indep }}<\pi^{v i}$.
}

ing franchising, competition between retailers, incentive compatible contracts, implicit understandings from repeated interaction, profit sharing, quantity discounts, coupons and rebates, exchange of personnel, and arbitration (Jeuland and Shugan 1983, Shugan 1985, McGuire and Staelin 1986, Lal 1990, Couglan et al. 1996, Gerstner and Hess 1995, Desiraju and Moorthy 1997). In this paper, we explore an alternative remedy: a manufacturer's direct channel.

\section{Direct Marketing}

Before beginning the complete analysis of this strategic use of direct marketing, we need to provide a model of consumer choice when the product can be purchased in a direct channel. A direct marketer provides consumers with only a virtual description of the product, using text, graphics, or symbols in a paper or web page catalog. This eliminates the use of touch, taste, smell, and often sound from the set of senses used in the prepurchase evaluation and can cause evaluation mistakes by shoppers. Even if the product may be returned after a mistaken purchase, the refund is typically only partial, therefore reducing the expectation of consumption value (Chu et al. 1998). If the product is purchased from a direct market, typically the consumer will be asked to wait several days for delivery and will be charged a shipping and handling fee (Hess et al. 1996). Finally, postsale service may be reduced because the seller is located at a distance. We incorporate these elements of direct markets into a simple model of consumer choice as follows.

A product that is worth $v$ if subject to a real inspection and immediate possesion has worth $\theta v$ when it is obtained from a direct channel with only a virtual inspection. The value of the parameter $\theta$ is called the customer acceptance of the direct channel. An empirical study by Liang and Huang (1998) shows that overall, consumers prefer conventional retail stores more than the web-based direct channels. Another recent survey (Kacen et al. 2002) provides further evidence (see Table 2) that the customer acceptance of webbased purchases is less than one for many product categories, i.e., most products are less acceptable from 
CHIANG, CHHAJED, AND HESS

Strategic Analysis of Dual-Channel Supply Chain Design

Table 2 Customers Acceptance Index $\theta$ for Web-Based Direct Channel Category Book Shoes Toothpaste DVD player Flowers Food items

$\begin{array}{lllllll}\text { Acceptance } & 0.904 & 0.769 & 0.886 & 0.787 & 0.792 & 0.784\end{array}$

Note. All product categories have $\theta$ below 1.0 at the $1 \%$ significance level.

a direct channel than a retailer. ${ }^{4}$ Therefore, the model in this paper is developed for those products with $0<\theta<1$. Note that $1-\theta$ is the proportionate loss of benefits from a direct channel purchase. As we will see next, this implies that the consumers divide continuously between the two channels.

\subsection{Demand in the Direct Channel}

If the product is sold in a direct channel at a price $p_{d}$ and the value of the product is $\theta v$, then the resulting consumer surplus is $\theta v-p_{d}$. If consumers can buy from either channel, their decisions revolve around the comparison of the consumer surplus derived from the retailer and direct marketer: $v-p_{r}$ versus $\theta v-p_{d}$. All consumers whose valuation satisfies $v-$ $p_{r} \geq 0$ would consider buying from the retailer. The marginal consumer whose valuation $v^{r}$ equals $p_{r}$ is indifferent to buying from the retailer or not at all. Equivalently, all consumers whose valuations satisfy $\theta v-p_{d} \geq 0$ would consider buying from the direct channel. The marginal consumer whose valuation $v^{d}$ equals $p_{d} / \theta$ is indifferent to buying from the direct marketer. Finally, if $v-p_{r} \geq \theta v-p_{d}$, then the traditional retailer is weakly preferred to the direct channel. The consumer whose valuation $v^{d r}$ equals $\left(p_{r}-\right.$ $\left.p_{d}\right) /(1-\theta)$ is indifferent between the two channels, and if the valuation exceeds this, they prefer the retailer. $^{5}$

\footnotetext{
${ }^{4}$ The attributes that affect customers' channel preference were easy to find product information, physical examination of products, immediate possession of products, uncertainty about getting the right item, accepts all forms of payment, helpfulness of salespeople, brand selection and variety, postpurchase service, exchange-refund policy for returns, quality of the merchandise, product found is in stock, ability to compare products, speed of selection and purchase, interesting social or family experience, charges for shipping and handling, and easy browsing for products.

${ }^{5}$ Because $\theta$ is the same for all consumers in this model, there is no advantage in trying to segment the market based upon customer acceptance of the direct channel.
}

One can show ${ }^{6}$ that in the case where $v^{d}<v^{r}$, then $v^{d}<v^{r}<v^{d r}$, and in the case where $v^{r}<v^{d}$, then $v^{d r}<$ $v^{r}<v^{d}$. In the former, all consumers with valuation in the interval $\left[v^{d}, v^{d r}\right]$ prefer to buy from the direct marketer, and all those in the interval $\left[v^{d r}, 1\right]$ prefer to buy from the retailer. Those shoppers whose valuations are in $\left[0, v^{d}\right]$ decline to buy the product from either channel. In the latter case, no customers want to buy from the direct marketer, and all those consumers whose valuations are in the interval $\left[v^{r}, 1\right]$ buy from the retailer.

Because the valuation of the consumers is uniformly distributed, demands for the retailer and direct channel correspond to piecewise-linear demand functions

$$
\begin{aligned}
& Q_{r}= \begin{cases}1-\frac{p_{r}-p_{d}}{1-\theta} & \text { if } \frac{p_{d}}{\theta} \leq p_{r}, \\
1-p_{r} & \text { otherwise, }\end{cases} \\
& Q_{d}= \begin{cases}\frac{\theta p_{r}-p_{d}}{\theta(1-\theta)} & \text { if } \frac{p_{d}}{\theta} \leq p_{r}, \\
0 & \text { otherwise. }\end{cases}
\end{aligned}
$$

Figure 2 illustrates the demand functions. The retailer's demand becomes more price elastic when the retail price exceeds $p_{d} / \theta$ as seen in Figure 2(a), because the retailer can lose customers to the direct channel. The value $p_{d} / \theta$ corresponds to the "real" price in the direct channel, correcting for the diminished benefit the product delivers. When the retail price is high, some of the consumers will find that the direct channel is the best choice even though they have to give up some of the value of the product, $(1-\theta) v$.

\subsection{Should a Vertically Integrated Firm Use the Direct Channel?}

A vertically integrated firm controls all three decisions: manufacturing, traditional retailing, and direct marketing. Given the demand functions in Equations (4)-(5), if the vertically integrated firm sets retail price

\footnotetext{
${ }^{6}$ Suppose that $v^{d}<v^{r}$ or $p_{d} / \theta<p_{r}$. Cross-multiply by $-\theta$, reversing the direction of the inequality, add $p_{r}$ to both sides, and divide both sides by $1-\theta$. This leaves $\left(p_{r}-p_{d}\right) /(1-\theta)>p_{r}$, which is equivalent to $v^{d r}>v^{r}$. The same steps are applicable when one starts with $v^{r}<v^{d}$.
} 


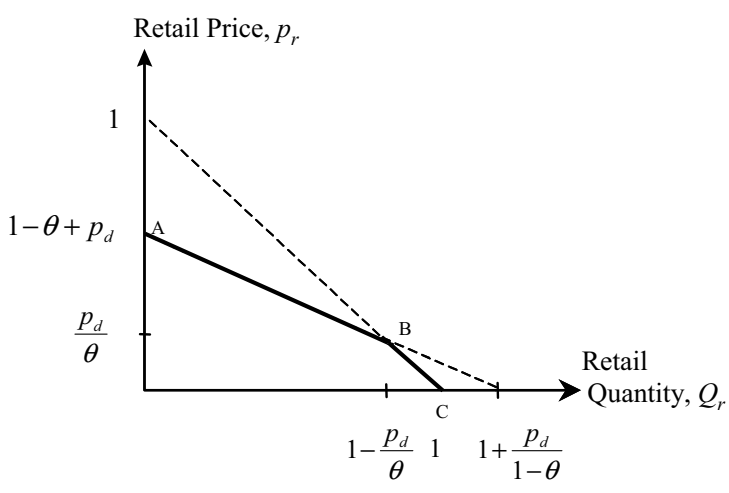

(a)

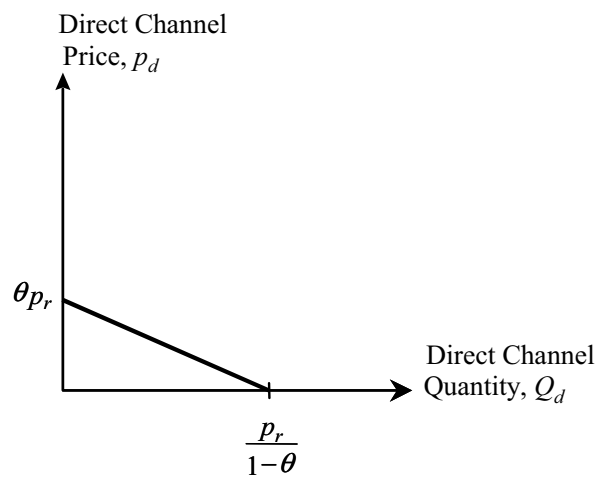

(b) $p_{r}$ and direct market price $p_{d}$, then the profits it would earn equal

$$
\pi_{v i}=\left(p_{r}-c_{r}\right) Q_{r}+\left(p_{d}-c_{d}\right) Q_{d}
$$

where $c_{r}$ and $c_{d}$ are marginal costs incurred by the manufacturer for the product sold through the retailer and direct channel, respectively. Because consumers pay for shipping and handling in a typical direct market, normally we would expect that $c_{d}<c_{r}$, but none of our results depends upon this. ${ }^{7}$ Maximizing $\pi_{v i}$ with respect to $p_{r}$ and $p_{d}$ requires that we take into account the piecewise-linear nature of the demand curves.

Begin by assuming that $p_{d} / \theta \leq p_{r}$, so that we can concentrate on the top lines of demand Equations (4) and (5):

$$
\begin{aligned}
\pi_{v i} & =\left(p_{r}-c_{r}\right) Q_{r}+\left(p_{d}-c_{d}\right) Q_{d} \\
& =\left(p_{r}-c_{r}\right)\left(1-\frac{p_{r}-p_{d}}{1-\theta}\right)+\left(p_{d}-c_{d}\right) \frac{\theta p_{r}-p_{d}}{\theta(1-\theta)}
\end{aligned}
$$

Maximizing this with respect to $p_{r}$ and $p_{d}$ gives $p_{r}=$ $\left(1+c_{r}\right) / 2$ and $p_{d}=\left(\theta+c_{d}\right) / 2$. This solution satisfies

\footnotetext{
${ }^{7}$ In the example of Table 1 , the manufacturing cost is $\$ 4.50$. The cost of shipping to the retailer is $\$ 0.50$, while the direct shipping costs to the consumer are almost three times higher at $\$ 1.33$ (note: $1-\theta=0.166$, the price is $\$ 8.00$, and $0.166 * 8=\$ 1.33$ ). However, the consumer pays a shipping and handling fee, so the manufacturer sees zero net shipping costs when selling direct. The net costs of both manufacturing and logistics incurred by the manufacturer are $c_{d}=\$ 4.50$ and $c_{r}=\$ 4.50+\$ 0.50=\$ 5.00$ when selling through the direct and retail channels, respectively.
}

$p_{d} / \theta \leq p_{r}$ only when $\theta \geq c_{d} / c_{r}$. If $\theta$ is smaller than $c_{d} / c_{r}$, we must have zero demand for the direct market (bottom line of Equation (5)). On the other hand, if $\theta$ is too large, the demand for the retailer will drop to zero as seen in Figure 2(a). This occurs when retail price equals $p_{r}=1-\theta+p_{d}$ or $\left(1+c_{r}\right) / 2=1-\theta+\left(\theta+c_{d}\right) / 2$. Rearranging this, when $\theta \geq 1-\left(c_{r}-c_{d}\right)$, the solution has hit a corner where there is zero demand in the retail market. ${ }^{8}$ Table 3 gives a complete characterization of the optimal decisions of a vertically integrated firm that could distribute through a retail or direct channel.

\section{Direct Marketing, Indirect Profits}

Reconsider the Stackelberg game first introduced in $\S 2$, where a monopolist manufacturer distributes its product through a single retailer under an exclusive territory arrangement. Now suppose that the manufacturer is considering opening a direct channel to the market. Unlike a vertically integrated firm, here the manufacturer and the retailer are independent decision-makers, and each looks at its own profit

\footnotetext{
${ }^{8}$ If $\theta>1$ (all consumers prefer to buy direct rather than retail) and $c_{d}<c_{r}$ (because buyers pay the shipping and handling), then the retail channel will be closed. In this case, direct marketing dominates retailing both by making the consumer more satisfied and by reducing costs. The manufacturer would want to switch to a single channel, dropping distribution through independent retailers. In this paper, we are interested in dual channels, and to keep the retailer viable, we focus on the case where $\theta<1$.
} 
CHIANG, CHHAJED, AND HESS

Strategic Analysis of Dual-Channel Supply Chain Design

\begin{tabular}{|c|c|c|c|}
\hline \multicolumn{4}{|c|}{ Impact of $\theta$ on channel design } \\
\hline Best channel strategy & $\begin{array}{l}0<\theta \leq c_{d} / c_{r} \\
\text { Retailer only }\end{array}$ & $\begin{array}{c}c_{d} / c_{r} \leq \theta \leq 1-\left(c_{r}-c_{d}\right)^{*} \\
\text { Dual-channel approach }\end{array}$ & $\begin{array}{c}1-\left(c_{r}-c_{d}\right) \leq \theta<1^{*} \\
\text { Direct channel only }\end{array}$ \\
\hline \multicolumn{4}{|l|}{ Price } \\
\hline Direct channel, $p_{d}$ & $\mathrm{n} / \mathrm{a}$ & $\frac{\theta+c_{d}}{2}$ & $\frac{\theta+2 c_{d}}{2 \theta}$ \\
\hline $\begin{array}{l}\text { Retail store, } p_{r} \\
\text { Sales volume }\end{array}$ & $\frac{1+c_{r}}{2}$ & $\frac{1+c_{r}}{2}$ & $\mathrm{n} / \mathrm{a}$ \\
\hline Direct channel, $Q_{d}$ & $\mathrm{n} / \mathrm{a}$ & $\frac{c_{r} \theta-c_{d}}{2 \theta(1-\theta)}$ & $\frac{\theta(2 \theta-1)-c_{d}}{2 \theta^{2}}$ \\
\hline Retail store, $Q_{r}$ & $\frac{1-c_{r}}{2}$ & $\frac{1}{2}-\frac{c_{r}-c_{d}}{2(1-\theta)}$ & $\mathrm{n} / \mathrm{a}$ \\
\hline $\begin{array}{l}\text { Total, } Q_{d}+Q_{r} \\
\text { Profit }\end{array}$ & $\frac{1-c_{r}}{2}$ & $\frac{1}{2}-\frac{c_{d}}{2 \theta}$ & $\frac{\theta(2 \theta-1)-c_{d}}{2 \theta^{2}}$ \\
\hline Direct channel, $\pi_{d}$ & $\mathrm{n} / \mathrm{a}$ & $\frac{\left(\theta-c_{d}\right)\left(c_{r} \theta-c_{d}\right)}{4 \theta(1-\theta)}$ & $\frac{\left(2 \theta^{2}-\theta-c_{d}\right)\left(\theta+c_{d}-2 \theta c_{d}\right)}{4 \theta^{3}}$ \\
\hline Retail store, $\pi_{r}$ & $\frac{\left(1-c_{r}\right)^{2}}{4}$ & $\frac{\left(1+c_{r}\right)\left[(1-\theta)-\left(c_{r}-c_{d}\right)\right]}{4(1-\theta)}$ & 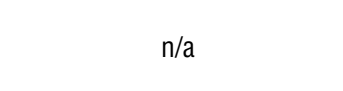 \\
\hline Total, $\pi_{d}+\pi_{r}$ & $\frac{\left(1-c_{r}\right)^{2}}{4}$ & $\frac{\left(1-c_{r}\right)^{2}}{4}+\frac{\left(c_{r}-c_{d}\right)^{2}}{4(1-\theta)}+\frac{c_{d}^{2}-\theta c_{r}^{2}}{4 \theta}$ & $\frac{\left(2 \theta^{2}-\theta-c_{d}\right)\left(\theta+c_{d}-2 \theta c_{d}\right)}{4 \theta^{3}}$ \\
\hline
\end{tabular}

when setting prices, ignoring the collective impact of the prices on the channel as a whole.

Recall that customer acceptance of the direct market, $\theta$, could be so small that a vertically integrated firm would not want to sell direct; economists would then characterize the direct market as inefficient. In what follows, we allow the independent manufacturer to choose whether or not to use the direct market without regard to its efficiency. We will show that a direct market may be used for profitable strategic purposes even though it is inefficient.

In this section, we incorporate the role of the direct channel into the Stackelberg game model to examine the interaction between the manufacturer and the retailer (see Figure 3). The game has the following sequence of moves. In the first stage, the manufacturer decides whether to engage in direct sales, and act as Stackelberg leader in setting the wholesale price $w$, and the direct channel price $p_{d}$ (if the direct channel is open). To keep the retailer from buying through the direct channel or other arbitrators with a lower price, the wholesale price should not be higher than the direct channel price, that is $w \leq$ $p_{d}$. The manufacturer maximizes its total profit $\pi_{m}=$ $\left(w-c_{r}\right) Q_{r}+\left(p_{d}-c_{d}\right) Q_{d}$, taking the retailer's behavior into account, where $Q_{r}$ and $Q_{d}$ are the demand functions given in Equations (4) and (5). In the second stage, the retailer, as a follower, chooses the retail price $p_{r}$ to maximize its profit $\pi_{r}=\left(p_{r}-w\right) Q_{r}$, given

Figure 3 Stackelberg Game with Direct Channel

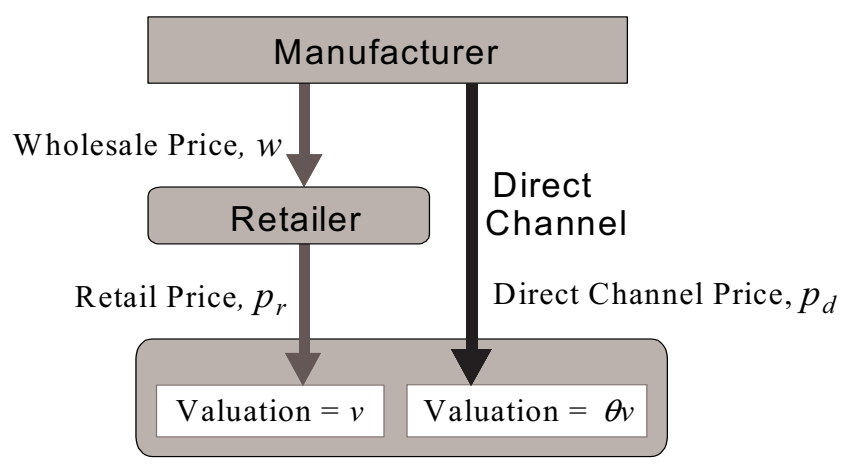


the manufacturer's decision, where the retail demand is given in Equation (4). To be certain that the game is subgame perfect, we first analyze the second-stage retailer's decisions followed by the first-stage manufacturer's decisions.

\subsection{The Retailer's Pricing Problem When Confronting a Direct Channel}

The retailer has control over only one variable to maximize its profit, the retail price $p_{r}$. To decide the optimal retail price $p_{r}^{*}$, the retailer must take into account the piecewise-linear demand $Q_{r}$ in Equation (4) and Figure 2(a). First, consider the optimal price along the upper line segment $\overline{A B}$ in Figure 2(a); along this segment, the direct price is so low that the retailer loses some customers to the direct market. It follows that $p_{r}^{*}=\left(1-\theta+p_{d}+w\right) / 2$, but only if this price exceeds or equals the price at the kink point $B, p_{d} / \theta$ (we have to ensure that it is in the line segment $\overline{A B}$ ). Explicitly, this retail price is optimal only when the manufacturer sets the direct channel price $p_{d}$ and the wholesale price $w$ in the price region $R_{1}$, where

$$
R_{1}=\left\{\left(p_{d}, w\right) \mid \frac{1-\theta+p_{d}+w}{2} \geq \frac{p_{d}}{\theta}, w \leq p_{d}\right\} .
$$

Next, consider the optimal price along the line segment $\overline{B C}$. This would be $p_{r}^{*}=(1+w) / 2$, but only if this price is less than or equal to $p_{d} / \theta$, i.e., this optimal retail price only reacts to the prices in region $R_{3}$ (region $R_{2}$ will be defined shortly), where

$$
R_{3}=\left\{\left(p_{d}, w\right) \mid \frac{1+w}{2} \leq \frac{p_{d}}{\theta}, w \leq p_{d}\right\} .
$$

Finally, if the manufacturer sets $\left(p_{d}, w\right)$ in neither region $R_{1}$ nor region $R_{3}$, then the optimal retail price is located at the kink point $B$ in the demand where the retail price is $p_{r}^{*}=p_{d} / \theta$. This is in response to the prices in region $R_{2}$, where

$$
R_{2}=\left\{\left(p_{d}, w\right) \mid \frac{1-\theta+p_{d}+w}{2} \leq \frac{p_{d}}{\theta}, \frac{1+w}{2} \geq \frac{p_{d}}{\theta}, w \leq p_{d}\right\} .
$$

The price regions $R_{1}, R_{2}$, and $R_{3}$ are illustrated in Figure 4 , and we formally state the retailer's best pricing strategy in the following theorem.

\section{Figure 4 Feasible Regions for Direct Market and Wholesale Prices}

Wholesale

Price, $w$

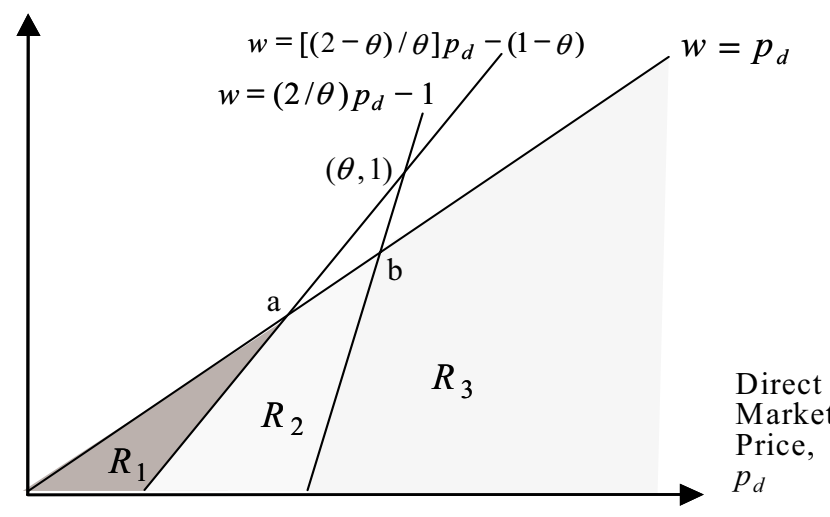

Region $R_{1}$ : Retail price on upper branch of demand, $\mathrm{AB}$ in Figure 2(a) Region $R_{2}$ : Retail price at kink point of demand, B in Figure 2(a)

Region $R_{3}$ : Retail price on lower branch of demand, BC in Figure 2(a)

Theorem 1 (Best Response of Retail Price). Given the manufacturer's decision of wholesale price $w$ and direct market price $p_{d}$, the optimal price for the retailer is

$$
p_{r}^{*}= \begin{cases}\frac{1-\theta+p_{d}+w}{2} & \text { if }\left(p_{d}, w\right) \in R_{1}, \\ \frac{p_{d}}{\theta} & \text { if }\left(p_{d}, w\right) \in R_{2}, \\ \frac{1+w}{2} & \text { if }\left(p_{d}, w\right) \in R_{3} .\end{cases}
$$

Given this solution of the retailer's pricing problem, what should the manufacturer do?

\subsection{The Manufacturer's Pricing Problem When Using Both Retail and Direct Channels}

Anticipating the retailer's choices, the manufacturer's problem is to maximize its total profits by choosing wholesale price $w$ and direct market price $p_{d}$ subject to $w \leq p_{d}$. The manufacturer cannot price discriminate by charging a higher wholesale price than direct price, because the retailer would costlessly switch its purchases to the direct channel and refuse to pay the higher wholesale price. The essence of the manufacturer's difficulty is that the retailer is grasping for profit margins by setting high retail prices, and the manufacturer would like to limit this "double marginalization" by offering to sell the product at a 
low direct price. There are three regions to be examined, as seen in Figure 4.

First, consider region $R_{1}$, where the direct channel price is so low that the retailer is focusing on the branch of demand $\overline{A B}$ above the kink in Figure 2(a). We show that it would be preferable to let the retailer completely choke off demand in the direct market.

LEMMA 1. The optimal prices in region $R_{1}$ are at point " $a$ ", where prices are at their highest levels in region $R_{1}$ : $\left(p_{d}^{*}, w^{*}\right)=(\theta / 2, \theta / 2)$.

The proof of Lemma 1 is given in Appendix 1, and the intuition is as follows. Raising both the wholesale and direct price by equal amounts causes the retailer to raise the retail price by an equal amount (see Equation (8)). Sales in the retail market are unchanged but direct sales slightly shrink. The gain in contribution margin on direct sales exactly covers the loss in direct sales volume, but the higher manufacturer margins on retail sales make the change profitable. The highest price in region $R_{1}$ is at point "a." This result implies that we can eliminate region $R_{1}$ from consideration for the manufacturer's pricing strategy because the optimal prices of this region, point "a," are also in region $R_{2}$. In fact, it can also be shown that point "a" cannot be optimal in region $R_{2} \cdot{ }^{9}$ Therefore, the prices at point "a" are profit dominated by other prices in region $R_{2}$.

Only in region $R_{1}$ does the direct channel have positive sales volume. However, as we have shown, a strategic manufacturer will set prices either in region $R_{2}$ or in region $R_{3}$ such that all consumers will prefer to buy from the retailer. Whether the optimal prices should be in region $R_{2}$ or $R_{3}$ will depend on the customer acceptance of direct channel. Notice that when the optimal prices are in region $R_{3}$, the optimal retail price would be on the branch of demand $\overline{B C}$ below the kink in Figure 2(a), and the resulting behavior would correspond to the problem of "double marginalization." In other words, the retail price and

${ }^{9}$ In region $R_{2}$, the manufacturer's profits are $\pi_{m}\left(p_{d}, w\right)=\left(w-c_{r}\right)$. $\left(1-p_{d} / \theta\right)$. If the manufacturer starts prices from point " $\mathrm{a}$ " and increases both $w$ and $p_{d}$ while keeping $w=p_{d}$ (moving along the line segment $\overline{a b}$ in Figure 4), then the marginal profit is

$$
\left.\frac{\partial \pi_{m}(w, w)}{\partial w}\right|_{w=\theta / 2}=\left.\frac{\theta+c_{r}-2 w}{\theta}\right|_{w=\theta / 2}=\frac{c_{r}}{\theta}>0 .
$$

the wholesale price are exactly identical to the equilibrium prices in the problem of "double marginalization" see footnote 2).

The details of the optimal solution to the manufacturer's pricing problem are found in Appendix 2, and the results are summarized below.

Theorem 2 (Manufacturer's Pricing Strategy). There exists a customer acceptance of direct channel, $\hat{\theta}$, which we call the cannibalistic threshold defined as

$$
\widehat{\theta}=\frac{\left(1+c_{r}\right)^{2}+\left(1-c_{r}\right) \sqrt{1+6 c_{r}+c_{r}^{2}}}{4},
$$

such that when $\theta$ exceeds the threshold, the optimal prices for the manufacturer are

$$
p_{d}^{*}=w^{*}=\frac{\theta+c_{r}}{2}
$$

and the corresponding retail price is $p_{r}^{*}=\left(\theta+c_{r}\right) / 2 \theta$. When $\theta$ falls below the threshold, the optimal prices correspond to the problem of "double marginalization."

Given the behavior of both retailer and manufacturer, how does the dual-channel system perform compared to the traditional supply-chain system without the direct channel?

\subsection{Channel Equilibrium and Implications}

The subgame perfect equilibrium of the Stackelberg pricing game describes the solution to the manufacturer's channel control problem. The related outcomes as well as the comparative statics are provided in Table 4.

The strategic use of the direct channel motivates the independent retailer to lower its price and increase sales volume. The effectiveness of this strategy depends upon the viability of the independent manufacturer's threat to sell directly to the consumers. The demand parameter $\theta$ captures this viability. In Figure 5, the manufacturer's profits are drawn as a function of customer acceptance of the direct channel.

From the manufacturer's viewpoint, when the customer acceptance of the direct channel is below the cannibalistic threshold (say, due to consumer perception of delays in direct delivery, potential mismatch of the catalog description, and performance of the 
CHIANG, CHHAJED, AND HESS

Strategic Analysis of Dual-Channel Supply Chain Design

Table 4 Outcomes of the Price-Setting Game Between Manufacturer and Retailer

\begin{tabular}{|c|c|c|c|c|}
\hline & \multicolumn{2}{|c|}{ Impact of $\theta$ on the price-setting game } & \multicolumn{2}{|c|}{ Comparative statics when $\theta \geq \hat{\theta}$} \\
\hline & $\theta \leq \hat{\theta}$ & $\theta \geq \hat{\theta}$ & Derivative w.r.t. $\theta$ & Sign of derivative \\
\hline \multicolumn{5}{|l|}{ Price } \\
\hline Wholesale, $w$ & $\frac{1+c_{r}}{2}$ & $\frac{\theta+c_{r}}{2}$ & $\frac{1}{2}$ & + \\
\hline Direct channel, $p_{d}$ & $\frac{1+c_{r}}{2}$ & $\frac{\theta+c_{r}}{2}$ & $\frac{1}{2}$ & + \\
\hline $\begin{array}{l}\text { Retail store, } p_{r} \\
\text { Sales volume, }\end{array}$ & $\frac{3+c_{r}}{4}$ & $\frac{\theta+c_{r}}{2 \theta}$ & $-\frac{C_{r}}{2 \theta^{2}}$ & - \\
\hline Direct channel, $Q_{d}$ & 0 & 0 & 0 & 0 \\
\hline Retail store, $Q_{r}$ & $\frac{1-c_{r}}{4}$ & $\frac{\theta-c_{r}}{2 \theta}$ & $\frac{c_{r}}{2 \theta^{2}}$ & + \\
\hline $\begin{array}{l}\text { Total, } Q_{d}+Q_{r} \\
\text { Profit }\end{array}$ & $\frac{1-c_{r}}{4}$ & $\frac{\theta-c_{r}}{2 \theta}$ & $\frac{c_{r}}{2 \theta^{2}}$ & + \\
\hline Manufacturer, $\pi_{m}$ & $\frac{\left(1-c_{r}\right)^{2}}{8}$ & $\frac{\left(\theta-c_{r}\right)^{2}}{4 \theta}$ & $\frac{\theta^{2}-c_{r}^{2}}{4 \theta^{2}}$ & + \\
\hline Retail store, $\pi_{r}$ & $\frac{\left(1-c_{r}\right)^{2}}{16}$ & $\frac{(1-\theta)\left(\theta^{2}-c_{r}^{2}\right)}{4 \theta^{2}}$ & $\frac{-\theta^{3}+(2-\theta) c_{r}^{2}}{4 \theta^{3}}$ & - \\
\hline Total, $\pi_{m}+\pi_{r}$ & $\frac{3\left(1-c_{r}\right)^{2}}{16}$ & $\frac{\left(\theta-c_{r}\right)\left(\theta-2 \theta c_{r}+c_{r}\right)}{4 \theta^{2}}$ & $\frac{(1-\theta) c_{r}^{2}}{2 \theta^{3}}$ & + \\
\hline
\end{tabular}

product, etc.), adding a direct channel to the market provides no threat to the retailer. The retailer can effectively ignore the potential cannibalization of customers by the direct market, so the manufacturer does not profit by adding a direct channel. On the other hand, when the customer acceptance of the

Figure 5 Manufacturer Profits and Direct Sales

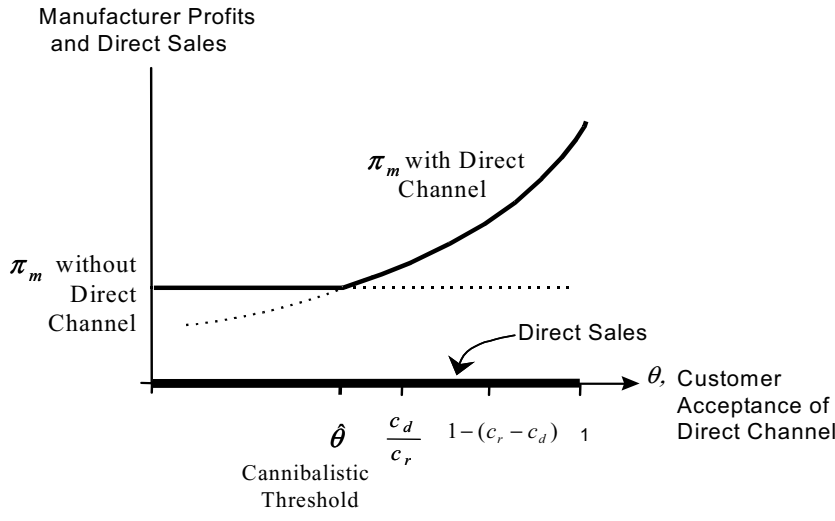

Note. This figure is drawn with $c_{d}<c_{r}$ for convenience. direct channel exceeds the cannibalistic threshold, $\hat{\theta}$, the consumer sees little distinction between a traditional retailer and a direct marketer. Because the direct channel is a serious threat to cannibalize retail sales, the retailer will more aggressively cut prices, partially resolving the double marginalization problem and as a consequence, increasing the manufacturer's profits.

When the manufacturer adds a direct channel to its distribution system, one might intuitively guess that a surge of customers would switch from the retailer to the direct channel. This does not happen, as is demonstrated in the fourth row of Table 4 and seen in Figure 5. It is in the manufacturer's self-interest, surprisingly, to price the direct channel so that the retailer has motive and opportunity to dominate the direct market.

THEOREM 3. No matter how well the direct channel is accepted by consumers, it is most profitable for the manufacturer to arrange prices so that nothing is ever sold in its own direct channel. 
Take an extreme case. When the customer acceptance of the direct channel is high, an integrated manufacturer-distributor would close the retail channel and sell only through the direct channel. ${ }^{10}$ This makes sense when the direct market is perceived to be almost equivalent to the retail market by customers and has a cost advantage. Remarkably, when $\theta$ is near one, an independent manufacturer introduces the direct channel as a sham: all products are sold through the inefficient retailer.

COROLlary 1. Even when the parameters are such that a vertically integrated manufacturer-distributor would sell only through the direct channel, the independent manufacturer uses this channel merely to control the independent retailer's pricing: no direct sales occur.

This result follows from the comparison of Tables 3 and 4 when customer acceptance of a direct channel is near one. We implicitly assume that the manufacturer is contractually committed to retail distribution. But why doesn't the manufacturer essentially drive the inefficient independent retailer out of business by pricing aggressively in the direct channel? It is true that total channel profits would be larger if the retail channel closed, but the independent retailer will vigorously protect its share of the channel profits if the only tools that the manufacturer can use are wholesale and direct prices. The direct market price discounts necessary to fight this particular battle make it unprofitable for the manufacturer.

Now, take the other extreme. An integrated manufacturer-distributor would not want to sell in a direct channel if the customer acceptance of the direct channel, $\theta$, falls short of $c_{d} / c_{r}$, the index of relative cost advantage of the direct channel (see the third row of Table 3). In Figure 5, there are values of acceptance of the direct channel above the cannibalistic threshold, $\hat{\theta}$, but below the "cost efficiency" threshold, $c_{d} / c_{r}$. In such a situation, an independent manufacturer would open a direct channel, but an integrated manufacturer-distributor would not.

THEOREM 4. Even when the parameters are such that a vertically integrated manufacturer-distributor would not

${ }^{10}$ The rightmost column of Table 1 , where $\theta$ exceeds $1-\left(c_{r}-c_{d}\right)$, shows that $Q_{r}=0$. use a direct channel, it is sometimes optimal for an independent manufacturer to open a direct channel although no direct sales occur.

This combination of opening a direct channel when it is economically inefficient, and the lack of intention to sell merchandise in this channel brings into stark relief the novel strategic purpose of direct marketing suggested by this model. The manufacturer benefits from opening an inactive direct channel because it mitigates the double marginalization problem with its retailer. One might characterize the optimal strategic use of direct marketing as passive-aggressive: the direct channel is a mild threat that can be easily overcome by the retailer, but only with retail price reductions. The profitable revenue stream flows more rapidly through the retail channel, but none is siphoned off by the direct channel.

\subsection{Pareto Zone}

Where the value of customer acceptance of the direct channel $\theta$ equals the cannibalistic threshold, $\hat{\theta}$, the manufacturer is indifferent between using the direct channel or not. Naturally, the manufacturer's profits increase with $\theta$ beyond this threshold (as seen in Table 4 and Figure 5). Moreover, total channel profits increase as the strategic use of the direct channel reduces the degree of double marginalization. It is interesting how retail profits depend upon customer acceptance of the direct channel.

The manufacturer uses the direct channel to hold the retailer's pricing in check. Should the retailer object to this manipulation of its decisions? Surprisingly, the retailer may have a stronger desire to credibly commit to lower prices than the manufacturer when customer acceptance of the direct channel is weak. Why? First, notice that all prices, including the wholesale price drop when the manufacturer introduces dual channels.

Theorem 5. The wholesale and retail prices are lower when the manufacturer uses dual channels than when it relies only on retail distribution.

From footnote 2 and Table 4, we learn that the wholesale price with only retailing, $\left(1+c_{r}\right) / 2$, is larger than that with dual channels, $\left(\theta+c_{r}\right) / 2$. The retail price is $\left(3+c_{r}\right) / 4$ with only retailing while it is 
$\left(\theta+c_{r}\right) /(2 \theta)$ with dual channels. It is easy to show that when $\theta$ exceeds the cannibalistic threshold, the retail price is lower with dual channels. Both of these price decreases were seen in Table 1, where wholesale price dropped from $\$ 7.50$ to $\$ 6.67$ and retail price dropped from $\$ 8.75$ to $\$ 8.00$ when dual channels were initiated. A direct consequence of the retail price reduction is that unit sales volume in the retail channel rises when a dual channel is used.

The wholesale price drop may be more precipitous than the retail price reduction if the direct channel is a weak threat ( $\theta$ is not too large). In this case, the customers do not like to buy from the direct channel, and the retailer gets a wholesale price reduction without the need to drop the retail price much to fend off the direct channel. Hence, retail profit margins increase if $\theta$ is not too large (specifically, if $\theta$ is below $\tilde{\theta} \equiv$ $\left.\left(1-c_{r}+\sqrt{1+14 c_{r}+c_{r}^{2}}\right) / 4\right)$.

The value of $\tilde{\theta}$ is found by setting the retail profit margin found in Table 4 that is equal to the retail profit margin in footnote 2 and solving for $\theta$. It can be shown that $\tilde{\theta}$ exceeds the cannibalization threshold. The retail margin diminishes if $\theta$ is larger and vanishes when it equals one (see Figure 6).

THeOREM 6. The retail profit margin increases when the manufacturer uses dual channels when $\theta \leq \tilde{\theta}$.

Combining the increased sales volume in the retail channel with the increased retail profit margin, the

\section{Figure 6 Retail and Wholesale Prices}

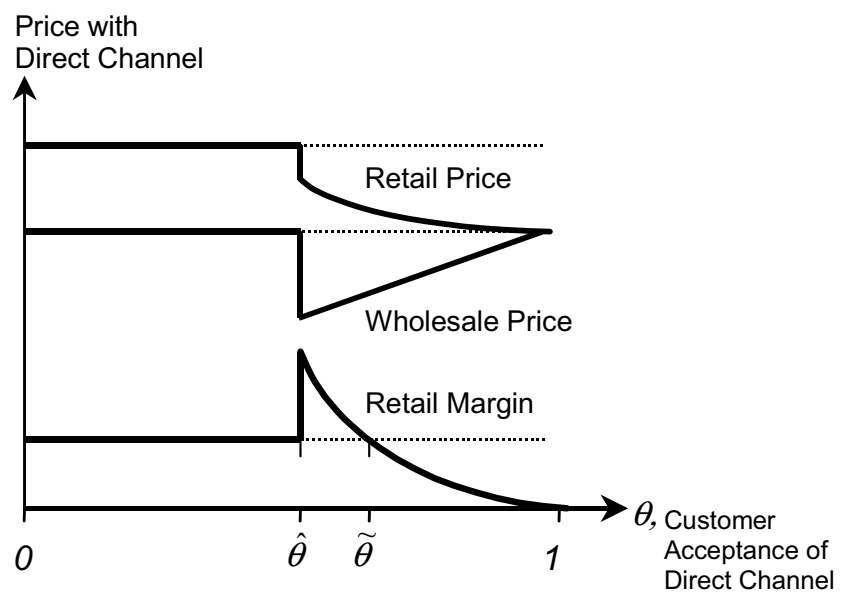

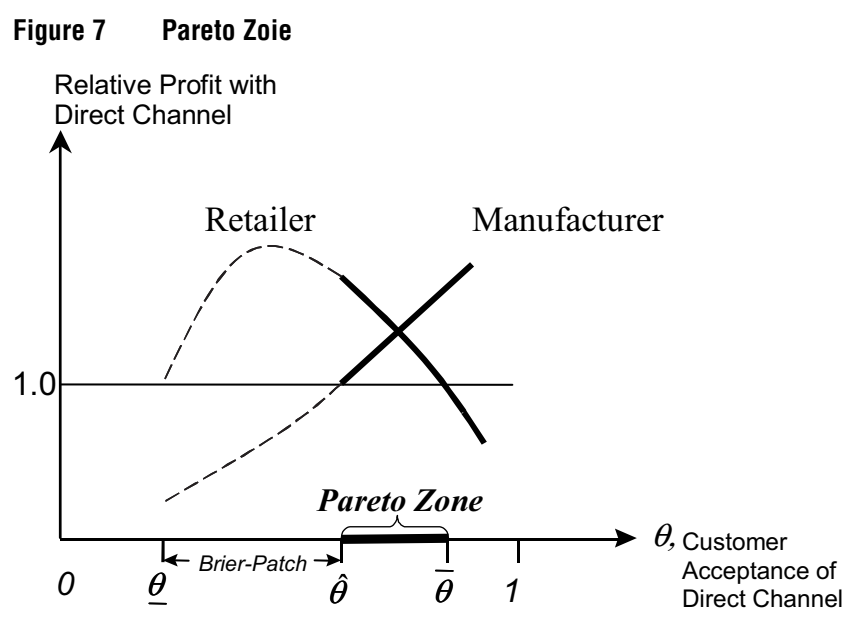

retailer can profit when the manufacturer introduces the dual channels. This unintended consequence occurs when the retailer's controlled profit, $(1-\theta)\left(\theta^{2}-c_{r}^{2}\right) /\left(4 \theta^{2}\right)$, exceeds the profits with double marginalization, $\left(1-c_{r}\right)^{2} / 16$. As seen in Figure 7, in the interval $[\underline{\theta}, \bar{\theta}]$, the retailer benefits from the competition with the direct channel. This interval is divided into the Pareto Zone and the Brier-Patch, as discussed next.

When customer acceptance of the direct channel is in the interval $(\hat{\theta}, \bar{\theta})$, both the retailer and manufacturer benefit from the partial solution of the doublemarginalization problem. The retailer benefits from higher margins (the wholesale price is reduced) and the manufacturer benefits from higher sales volume that results from retail price reductions. Because the strategic use of the direct channel makes both sellers more profitable, we call this interval the Pareto Zone. The following result is proved in Appendix 3.

Theorem 7 (Pareto Zone). There always exists a nonempty interval of customer acceptance of the direct channel, $(\hat{\theta}, \bar{\theta})$, where both the independent manufacturer and independent retailer are more profitable if the manufacturer opens the direct channel to compete with the retailer.

When acceptance of the direct channel falls in the other interval, $(\underline{\theta}, \hat{\theta}]$ in Figure 7 , the retailer finds it profitable to be put into competition with a direct channel. Even if there were significant costs to setting up a website or designing a catalog, the retailer would be happy to do this on the manufacturer's behalf in 
this region if the wholesale price reduction is guaranteed. However, the wholesale price concessions are too great and the increase in sales volume is too small to improve the manufacturer's profits. The manufacturer would make a mistake to allow this, and for that reason, we call the interval $(\underline{\theta}, \hat{\theta}]$ the Brier-Patch. ${ }^{11}$ Both the Pareto Zone and Brier-Patch suggest that retailers think carefully before complaining when a manufacturer opens its own direct channel. An unintended consequence of the direct channel on wholesale prices may leave the retailer better off.

Finally, and perhaps most realistically, when acceptance of the direct channel exceeds $\bar{\theta}$, the retailer would prefer not to compete against the manufacturer's direct channel because it is a serious alternative to the retail market for consumers. The best that the retailer can do in this competitive situation is significantly cut prices and this reduces profits. It is easy to see from Table 2 that as $\theta$ approaches 1 , the manufacturer extracts all the profits of the retailer.

\section{Channel Power and Division of Cooperative Profits}

We have demonstrated that when the retail channel is inefficient, the manufacturer's direct channel alleviates double marginalization and improves efficiency when the customer acceptance level of the direct channel is high enough. However, the most straightforward method of improving retail channel efficiency is cooperation in setting prices, though in many situations, there are problems achieving such cooperation (see Jeuland and Shugan 1983). Suppose that price coordination has been achieved, and the retail channel is efficiently pricing. Is direct entry still desirable for the manufacturer? In this section, we explore how the direct channel functions as a mechanism for the

${ }^{11}$ A classic case of psychological paradoxing is found in Joel C. Harris's The Complete Tales of Uncle Remus (1976), popularized by Disney Studios. Brer Fox was going to skin the sassy Brer Rabbit until he heard, "'Please, don't fling me in the brier-patch, Brer Fox,' sez Brer Rabbit, sezee." When Brer Fox slung Brer Rabbit in the brier-patch, all he heard was the wisecrack, "Bred en bawn in a brier-patch, Brer Fox-bred en bawn in a brier-patch"! The retailer plays the role of Brer Rabbit in this metaphor while the manufacturer is Brer Fox. manufacturer to capture a larger share of cooperative profits.

Table 3 suggests that when the customer acceptance of the direct channel is below $c_{d} / c_{r}$, the retail channel is the most efficient way to distribute the products. Clearly, in this case, direct entry is not desirable for the supply-chain system as a whole. In what follows, we will show that even though the retail channel is already efficient through price coordination and direct entry won't improve the overall channel profits, the direct channel may still be used by the manufacturer to increase its bargaining power in division of cooperative profits.

If the price coordination can be achieved and the double-marginalization problem is "solved," the additional profits from coordination must still be divided between the manufacturer and the retailer. The negotiated division depends in part on the fallback position that each party has if the bargaining reaches an impasse. If the only possibility to reaching agreement is continue with the double-marginalized pricing, then the "disagreement" profits are $\left(1-c_{r}\right)^{2} / 8$ and $\left(1-c_{r}\right)^{2} / 16$, for the manufacturer and the retailer, respectively. These are the disagreement outcomes represented in Figure 8 as point $m$. If channel coordination could be achieved by using other tools like quantity discounts, any profit division represented by a point on the line segment $\overline{a b}$ will satisfy the indi-

\section{Figure 8 Division of Cooperative Profits}

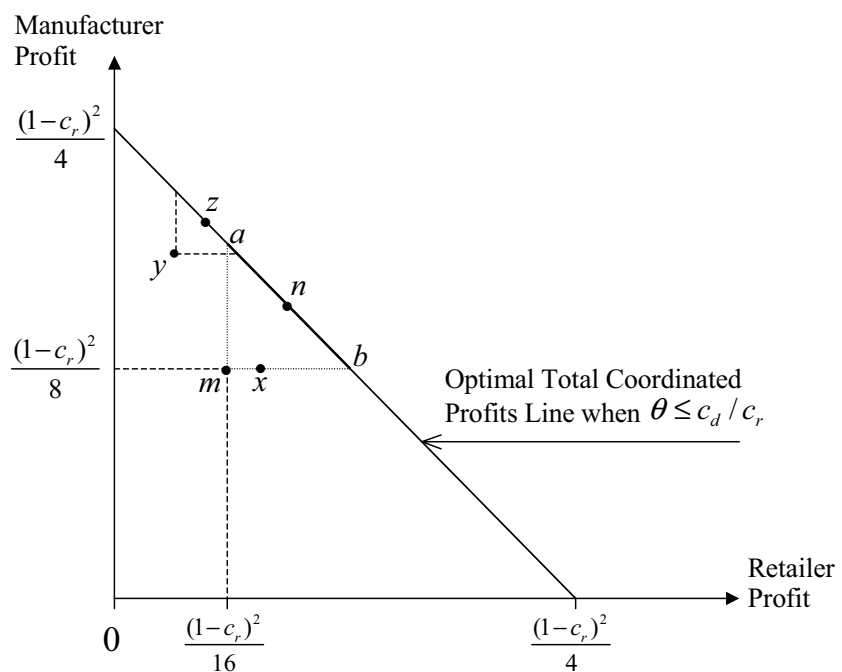

Management Science/Vol. 49, No. 1, January 2003 
vidually rational Pareto criterion. ${ }^{12}$ Determining the profit division is a well-known problem in bargaining theory, and the Nash bargaining solution (Nash 1950) predicts that the midpoint of the line segment $\overline{a b}$, point $n$, will be chosen.

However, if the possibility of introducing a direct market is a determinant of this disagreement position, then the magnitude of this disagreement outcome depends on the level of consumer acceptance of the direct channel, $\theta$. When $\theta<\hat{\theta}$, the direct channel is not a viable threat, and we know from Table 4 that the optimal profits are the same as those at point $m$.

When $\theta=\hat{\theta}$, the disagreement outcome is located at point $x$. This reflects the fact that at the left edge of the Pareto Zone in Figure 7, the retailer has positive benefits from channel coordination and the manufacturer does not. Its stronger fallback position implies that the retailer can bargain for a larger share of the cooperative profits. Paradoxically, the manufacturer's ability to introduce direct marketing to coordinate the channel hurts its bargaining power in a relative sense. This argument also holds for values of $\theta$, slightly above the cannibalistic threshold.

As demonstrated in Figure 7, for larger values of $\theta$, the relative advantage of the retailer diminishes, and there must exist a value of customer acceptance of the direct channel such that the corresponding threat is at a point like point $y$ in Figure 8 . At point $y$, the direct market is such a strong threat that the retailer has lower profits than if the channel was uncoordinated. The Nash bargaining solution of the division of cooperative profits favors the manufacturer at point $z$.

THEOREM 8. Suppose that the retail channel is efficient through price coordination (the double-marginalization problem is solved). The option of introduction of the direct market still influences the bargaining positions of the manufacturer and retailer through the disagreement position, and even if the direct channel is inefficient, the threat of introducing the direct channel can increase the manufacturer's share of cooperative profits.

\footnotetext{
12 This line segment is under the assumption that the direct channel is inefficient, $\theta<c_{d} / c_{r}$, but similar reasoning applies to the case of efficiency, $\theta>c_{d} / c_{r}$.
}

\section{Oligopolistic Retailers}

In this section, we extend our model by investigating the case of $n$ independent retailers who are identical and directly compete with each other. Our intention is to see if the direct channel can alleviate double marginalization when there is more than one retailer in the market. With this intention, the game is constructed with the following sequence of moves. In a prior stage, the manufacturer moves as Stackelberg leader as usual and chooses the wholesale price $w$ and the direct channel price $p_{d}$. After learning the wholesale price and the direct channel price, the retailers independently and simultaneously decide on a quantity and place an order with the manufacturer for the product. Finally, the product is available in the retail stores as well as the direct market, and the retailers engage in Bertrand-like price competition with the proviso that one cannot satisfy more demand than the quantity ordered in the previous stage.

Kreps and Scheinkman (1983) have shown that this type of quantity precommitment price competition will lead to the Cournot equilibrium where the retailers have the same price, and that price equates total supply and demand. Thus, in equilibrium, the retailers will set the same retail price $p_{r}$ that equates the total supply with demand. The equilibrium prices are given in the following theorem, and is proved in Appendix 4.

Theorem 9 (Oligopolistic Retailers). The equilibrium prices of the Stackelberg game of a single manufacturer serving $n$ competing retailers are as follows:

$$
\begin{aligned}
& p_{d}=w= \begin{cases}\frac{1+c_{r}}{2} & \text { if } \theta \leq \theta_{n}, \\
\frac{\theta+c_{r}}{2} & \text { otherwise, }\end{cases} \\
& p_{r}= \begin{cases}\frac{n+2+n c_{r}}{2(n+1)} & \text { if } \theta \leq \theta_{n}, \\
\frac{\theta+c_{r}}{2 \theta} & \text { otherwise, }\end{cases}
\end{aligned}
$$

where $\theta_{n}$ is the cannibalistic threshold and

$$
\theta_{n}=\frac{n+2 c_{r}+c_{r}^{2} n+\left(1-c_{r}\right) \sqrt{n^{2}\left(1+c_{r}\right)^{2}+4 n c_{r}}}{2(1+n)} .
$$


CHIANG, CHHAJED, AND HESS

Strategic Analysis of Dual-Channel Supply Chain Design

Figure 9 Cannibalistic Threshold Increases as the Number of Retailers Increases

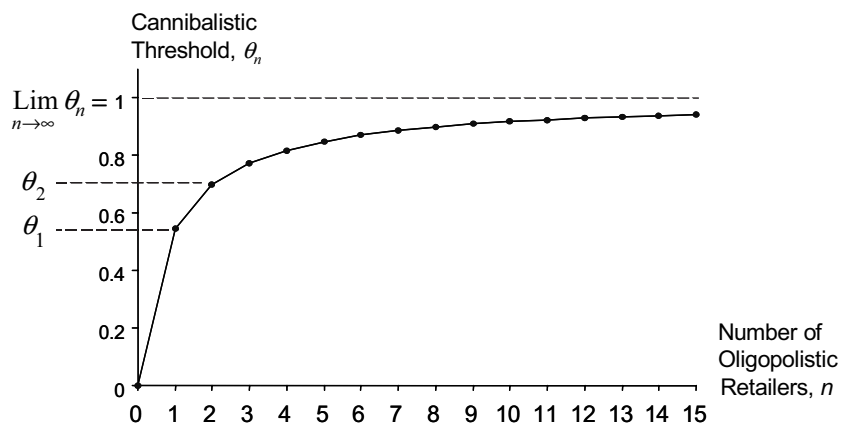

When there is only one retailer in the market $(n=1)$, the cannibalistic threshold $\theta_{1}$ is exactly identical to $\hat{\theta}$ in Equation (9). It can be shown that the value of the cannibalistic threshold increases as the number of retailers increases $\left(\theta_{n} \leq \theta_{n+1}\right.$ for all $\left.n \geq 1\right)$, and the value approaches one as the number of retailers goes to infinity (see Figure 9). These results imply that the strategic use of the direct channel to enhance the channel efficiency (without actually selling products direct) may still be viable even if the manufacturer is dealing with oligopolistic retailers. However, the minimum required customer acceptance of the direct channel to implement the strategy, the cannibalistic threshold, is higher when more retailers are competing in the market. Not surprisingly, the strategic value of the direct channel is eliminated by perfect competition.

\section{Concluding Remarks}

Is a direct channel helpful to the manufacturer? How and why? Our model provides a novel answer focusing on channel control. Without a direct channel, the manufacturer and retailer acting independently (rather than as a single integrated unit) create a higher retail price, lower sales, and lower profits than is efficient. The manufacturer can mitigate these losses by the introduction of a direct channel if a direct channel is a viable threat to draw customers away from the retailer. When the direct channel is opened in this circumstance, it induces the retailer to lower the price, which, in turn, spurs demand in the retail channel. The manufacturer is more profitable even if no sales occur in the direct channel.
In a sense, the direct channel is a sham-its sole purpose in this circumstance is to improve the functioning of the retail channel by preventing the prices from being too high. The notable strategic use of a direct channel to increase channel efficiency is the main result of this paper. This also extends to an oligopolistic setting where the manufacturer faces several retailers. We also demonstrate that a negative reaction by retailers to manufacturers who open their own direct channels may be misguided. A consequence of the new direct market is that the manufacturer lowers wholesale prices, and as a result, the profits of the retailer may actually rise.

In this paper, the viability of the direct channel is captured by customer acceptance of the direct channel-the degree to which customers accept a direct channel as a substitute for shopping at a traditional store. The empirical surveys by Liang and Huang (1998) and Kacen et al. (2002) have shown that the direct channel may not be as well accepted as the traditional retail channel for many product categories. Therefore, our model, which assumes that customer acceptance of the direct channel is less than one, corresponds to empirically most likely cases.

Realistically, we would expect that no matter how small, there would always be some sales volume in an open direct channel. Zero direct sales occur in our model because we assumed homogeneity of customer acceptance of the direct channel. If there was a small additional segment that accepted the direct channel as a better substitute $(\theta \geq 1)$, then it can be shown that positive sales may occur, even though controlling the retailer's pricing remains the primary justification of the direct channel.

Future work on this topic should include an investigation of the factors that determine customer acceptance of the direct channel. Is customer acceptance of the direct channel different for various segments? If so, how and why? What happens when competition is introduced among manufacturers? An extension of the model to multiple periods where customer acceptance of the direct channel changes over time would also add insight to strategic supply-chain design. Finally, the retailer may provide pre- and postsale services that make products more valuable to the consumers and, hence, may expand unit sales. However, 
the retailer will consider only its own profit in choosing service levels, ignoring the profits that the manufacturer earns from expanded sales. The analysis of the model, which incorporates the service levels into the demand function, may be interesting.

\section{Acknowledgments}

The authors thank the associate editor and two anonymous referees for their valuable comments. They also thank Jacqueline Kacen for improvements in style and clarity.

\section{Appendix 1. Proof of Optimal Prices in Region $R_{1}$} If the manufacturer sets $\left(p_{d}, w\right)$ in region $R_{1}$, the demand of the retailer and the direct channel are, respectively,

$$
\begin{aligned}
& Q_{r}=1-\frac{p_{r}-p_{d}}{1-\theta}, \\
& Q_{d}=\frac{\theta p_{r}-p_{d}}{\theta(1-\theta)},
\end{aligned}
$$

and the retail price is $p_{r}=\left(1-\theta+p_{d}+w\right) / 2$. Substituting in (A1) and (A2), it follows that

$$
\begin{aligned}
Q_{r} & =\frac{1-\theta+p_{d}-w}{2(1-\theta)}, \\
Q_{d} & =\frac{\theta(1-\theta)-(2-\theta) p_{d}+\theta w}{2 \theta(1-\theta)} .
\end{aligned}
$$

The optimal prices in region $R_{1}$ correspond to the solution of the following quadratic program:

$$
\begin{aligned}
\underset{p_{d}, w}{\operatorname{maximize}} & \left(w-c_{r}\right) \frac{(1-\theta)+p_{d}-w}{2(1-\theta)} \\
& +\left(p_{d}-c_{d}\right) \frac{\theta(1-\theta)-(2-\theta) p_{d}+\theta w}{2 \theta(1-\theta)} \\
\text { s.t. } & -p_{d}+w \leq 0, \quad(2-\theta) p_{d}-\theta w \leq \theta(1-\theta) .
\end{aligned}
$$

We define the following matrix notations:

$$
\begin{aligned}
& \mathbf{x}=\left[\begin{array}{l}
p_{d} \\
w
\end{array}\right], \quad \mathbf{Q}=\left[\begin{array}{cc}
-\frac{2-\theta}{\theta(1-\theta)} & \frac{1}{1-\theta} \\
\frac{1}{1-\theta} & -\frac{1}{1-\theta}
\end{array}\right], \\
& \mathbf{q}=\left[\begin{array}{c}
\frac{\theta(1-\theta)-\theta c_{r}+(2-\theta) c_{d}}{2 \theta(1-\theta)} \\
\frac{(1-\theta)+c_{r}-c_{d}}{2(1-\theta)}
\end{array}\right], \\
& \mathbf{A}=\left[\begin{array}{cc}
-1 & 1 \\
2-\theta-\theta
\end{array}\right], \quad \mathbf{b}=\left[\begin{array}{c}
0 \\
\theta(1-\theta)
\end{array}\right] .
\end{aligned}
$$

The quadratic program can be rewritten as the matrix form

$$
\begin{aligned}
\max & \pi_{m}=\frac{1}{2} \mathbf{x}^{t} \mathbf{Q x}+\mathbf{q}^{t} \mathbf{x}-\frac{c_{r}+c_{d}}{2} \\
\text { s.t. } & \mathbf{A x} \leq \mathbf{b} .
\end{aligned}
$$

REMARK. $Q$ is negative definite for all $0<\theta<1$ :

$$
\begin{aligned}
& \Delta_{1}=-\frac{2-\theta}{\theta(1-\theta)}<0 \quad \forall \theta \in(0,1), \\
& \Delta_{2}=\frac{2}{\theta(1-\theta)}>0 \quad \forall \theta \in(0,1) .
\end{aligned}
$$

\section{Lagrangian Dual Problem}

The Lagrangian dual problem is to minimize $L(\mathbf{x}, \lambda)$ over $\lambda \leq \mathbf{0}$, where

$$
L(\mathbf{x}, \lambda)=\sup \left\{\frac{1}{2} \mathbf{x}^{t} \mathbf{Q} \mathbf{x}+\mathbf{q}^{t} \mathbf{x}+\lambda^{t}(\mathbf{A x}-\mathbf{b}): \mathbf{x} \in \mathbf{R}^{2}\right\} .
$$

Because $\mathbf{Q}$ is negative definite, for a given $\lambda, L(\mathbf{x}, \lambda)$ is concave. Hence, the unique maximizer $\mathbf{x}^{*}$ of $L(\mathbf{x}, \lambda)$ is determined by equating the gradient of $L(\mathbf{x}, \lambda)$ to zero, that is,

$$
\mathbf{Q x} \mathbf{x}^{*}+\mathbf{A} \lambda+\mathbf{q}=\mathbf{0}
$$

Therefore,

$$
\mathbf{x}^{*}=-(\mathbf{A} \lambda+\mathbf{q}) \mathbf{Q}^{-1} .
$$

Substituting in $L(\mathbf{x}, \lambda)$, it follows that

$$
L\left(\mathbf{x}^{*}, \lambda\right)=-\frac{1}{2} \lambda^{t}\left(\mathbf{A} \mathbf{Q}^{-1} \mathbf{A}^{t}\right) \lambda-\lambda^{t}\left(\mathbf{b}+\mathbf{A} \mathbf{Q}^{-1} \mathbf{q}\right)-\frac{1}{2} \mathbf{q}^{t} \mathbf{Q}^{-1} \mathbf{q} .
$$

The first-order condition with respect to $\lambda$ is

$$
-\lambda^{t}\left(\mathbf{A} \mathbf{Q}^{-1} \mathbf{A}^{t}\right)-\left(\mathbf{b}+\mathbf{A} \mathbf{Q}^{-1} \mathbf{q}\right)^{t}=0 .
$$

As a result,

$$
\lambda=\left[\begin{array}{l}
\lambda_{1} \\
\lambda_{2}
\end{array}\right]=-\left(\mathbf{A} \mathbf{Q}^{-1} \mathbf{A}^{t}\right)^{-1}\left(\mathbf{b}+\mathbf{A} \mathbf{Q}^{-1} \mathbf{q}\right)=\left[\begin{array}{c}
-\frac{(1-\theta)+c_{r}}{2(1-\theta)} \\
-\frac{c_{d}}{2 \theta(1-\theta)}
\end{array}\right] .
$$

It can be easily verified that $\boldsymbol{\lambda}<\mathbf{0}$ for all $0<\theta<1$. Consequently, the problem has only one solution:

$$
\mathbf{x}^{*}=-\mathbf{Q}^{-1}\left(\lambda^{t} \mathbf{A}+\mathbf{q}^{t}\right)=\left[\begin{array}{c}
\frac{\theta}{2} \\
\frac{\theta}{2}
\end{array}\right] .
$$

\section{Appendix 2. Proof of Theorem 2 (Equilibrium Prices)}

The subgame perfect equilibrium of the Stackelberg game corresponds to the solution of the maximization problem

$$
\begin{aligned}
\underset{\left[\left(p_{d}, w\right), p_{r}^{*}\right] \in \Phi \times \Re^{+}}{\operatorname{maximize}} & \pi_{m}\left(p_{d}, w, p_{r}^{*}\right) \\
\text { s.t. } & p_{r}^{*} \in \underset{p_{r} \in \Re^{+}}{\operatorname{argmax}} \pi_{r}\left(p_{d}, w, p_{r}\right),
\end{aligned}
$$

where $\Phi=\left\{\left(p_{d}, w\right) \mid w \leq p_{d} ; w, p_{d} \in \mathfrak{R}^{+}\right\}$. The problem can be decomposed into three subproblems $\mathbf{S P}_{i}, i=1,2,3$. Let $\pi_{i}^{*}$ be the optimal profit of $\mathbf{S P}_{i}$. Then,

$$
\begin{aligned}
\pi_{i}^{*}=\underset{\left[\left(p_{d}, w\right), p_{r}^{*}\right] \in R_{i} \times \Re^{+}}{\operatorname{maximize}} & \pi_{m}\left(p_{d}, w, p_{r}^{*}\right) \\
\text { s.t. } & (8) .
\end{aligned}
$$


CHIANG, CHHAJED, AND HESS

Strategic Analysis of Dual-Channel Supply Chain Design

From the analysis of Lemma 1, we learn that the optimal solution will be either in region $R_{2}$ or in region $R_{3}$. This implies that the optimal profit for the manufacturer is $\pi_{m}^{*}=\operatorname{Max}\left\{\pi_{2}^{*}, \pi_{3}^{*}\right\}$. As a result, we only have to focus on $\mathbf{S P}_{2}$ and $\mathbf{S P}_{3}$ to find the equilibrium prices.

In $\mathbf{S P}_{2}$, the manufacturer sets $\left(p_{d}, w\right)$ in region $R_{2}$ so that the retailer chooses the retail price $p_{r}^{*}=p_{d} / \theta$. With such a retail price, no customers will be willing to buy from the direct channel and the sales volume for the retailer $Q_{r}=1-p_{d} / \theta$. Therefore, $\mathbf{S P}_{2}$ is equivalent to

$$
\begin{aligned}
\underset{p_{d}, w}{\operatorname{maximize}} & \pi_{2}\left(p_{d}, w\right)=\left(w-c_{r}\right)\left(1-\frac{p_{d}}{\theta}\right) \\
\text { s.t. } & w \leq p_{d}, \\
& \frac{1-\theta+p_{d}+w}{2} \leq \frac{p_{d}}{\theta}, \\
& \frac{1+w}{2} \geq \frac{p_{d}}{\theta} .
\end{aligned}
$$

Following Lemma 1, we have shown that point "a" cannot be the optimal solution. This implies that constraint (A4) is redundant. Also, it can be shown that constraint (A3) must bind. Accordingly, we obtain the optimal solution to $\mathbf{S P}_{2}$, which depends on the following condition:

$$
c_{r}(2-\theta) \leq \theta^{2} .
$$

If (A5) is true, then the optimal prices are at point " $b$ " in Figure 4:

$$
\left(p_{d}, w\right)=\left(\frac{\theta}{2-\theta}, \frac{\theta}{2-\theta}\right),
$$

otherwise,

$$
\left(p_{d}, w\right)=\left(\frac{\theta+c_{r}}{2}, \frac{\theta+c_{r}}{2}\right)
$$

In $\mathbf{S P}_{3}$, the retailer chooses the retail price $p_{r}^{*}=(1+w) / 2$ because $\left(p_{d}, w\right)$ is in region $R_{3}$. There is no demand in the direct channel in this subproblem, and the sales volume for the retailer is $Q_{r}=$ $(1-w) / 2$. Consequently, $\mathbf{S P}_{3}$ can be written as

$$
\begin{aligned}
\underset{p_{d}, w}{\operatorname{maximize}} & \pi_{3}\left(p_{d}, w\right)=\left(w-c_{r}\right) \frac{1-w}{2} \\
\text { s.t. } & w \leq p_{d}, \\
& \frac{1+w}{2} \leq \frac{p_{d}}{\theta} .
\end{aligned}
$$

Because $p_{d}$ can be arbitrarily large because the objective function (A8) does not depend on it, constraints (A9) and (A10) are trivial. We have the optimal solution in region $R_{3}$ as follows:

$$
\left(p_{d}, w\right)=\left(\frac{1+c_{r}}{2}, \frac{1+c_{r}}{2}\right)
$$

We learn that prices in (A6), (A7), and (A11) are three candidates for the equilibrium. The optimal prices in (A6) are prices at point " $\mathrm{b}$ " in Figure 4. Because point " $\mathrm{b}$ " is in both region $R_{2}$ and region $R_{3}$, and is not the optimal solution to $\mathbf{S P}_{3}$, we know that if condition (A5) is true, then instead of setting prices at point " $b$," it will be more profitable for the manufacturer to set prices to the optimal prices obtained in $\mathbf{S P}_{3}$. Therefore, point " $b$ " cannot be the equilibrium prices and can be excluded from consideration. Now, either (A7) or (A11) can be the equilibrium prices. If

$$
\pi_{2}\left(\frac{\theta+c_{r}}{2}, \frac{\theta+c_{r}}{2}\right) \geq \pi_{3}\left(\frac{1+c_{r}}{2}, \frac{1+c_{r}}{2}\right),
$$

or if

$$
\theta \geq \frac{\left(1+c_{r}\right)^{2}+\left(1-c_{r}\right) \sqrt{1+6 c_{r}+c_{r}^{2}}}{4}
$$

then prices in Equation (A7) are the equilibrium prices; otherwise, the equilibrium prices are that in (A11).

\section{Appendix 3. Proof of Theorem 7 (Pareto Zone)}

From Table 4, we have

$$
\pi_{r}(\theta)= \begin{cases}\frac{\left(1-c_{r}\right)^{2}}{16} & \text { if } \theta<\hat{\theta} \\ \frac{(1-\theta)\left(\theta^{2}-c_{r}^{2}\right)}{4 \theta^{2}} & \text { otherwise. }\end{cases}
$$

Now, we want to prove $\pi_{r}(\hat{\theta})>\pi_{r}(\hat{\theta}-\epsilon)$ :

$$
\begin{aligned}
\pi_{r}(\hat{\theta})-\pi_{r}(\hat{\theta}-\epsilon) & =\frac{(1-\hat{\theta})\left(\hat{\theta}^{2}-c_{r}^{2}\right)}{4 \hat{\theta}^{2}}-\frac{\left(1-c_{r}\right)^{2}}{16} \\
& =\frac{3 \hat{\theta}^{2}-4 c_{r}^{2}-4 \hat{\theta}^{3}+4 \hat{\theta} c_{r}^{2}+2 \hat{\theta}^{2} c_{r}-\hat{\theta}^{2} c_{r}^{2}}{16 \hat{\theta}^{2}} \\
& =\frac{\varphi\left(c_{r}\right)}{16 \hat{\theta}^{2}}
\end{aligned}
$$

where

$$
\begin{aligned}
\varphi\left(c_{r}\right)=\frac{1}{8}\left(1-c_{r}\right)^{2}\left(1-3 c_{r}^{4}-20 c_{r}^{3}-22 c_{r}^{2}+4 c_{r}\right. \\
\left.\quad+\sqrt{\left(1+6 c_{r}+c_{r}^{2}\right)}\left(3 c_{r}^{3}+11 c_{r}^{2}+c_{r}+1\right)\right) \\
>\frac{1}{8}\left(1-c_{r}\right)^{2}\left(1-3 c_{r}^{4}-20 c_{r}^{3}-22 c_{r}^{2}+4 c_{r}\right. \\
\left.\quad+\left(1+\frac{3}{2} c_{r}\right)\left(3 c_{r}^{3}+11 c_{r}^{2}+c_{r}+1\right)\right) \quad \forall c_{r} \in[0,1) \\
=\frac{1}{16}\left(1-c_{r}\right)^{3}\left(c_{r}\left(17-3 c_{r}^{2}\right)+\left(4-2 c_{r}^{2}\right)\right)>0 \quad \forall c_{r} \in[0,1) .
\end{aligned}
$$

Note that the basic assumption for maintaining the business is that the marginal cost, $c_{r}$, is smaller than the maximum customer valuation, 1 . Thus, from (A12), we have

$$
\pi_{r}(\hat{\theta})>\pi_{r}(\hat{\theta}-\epsilon)>\pi_{r}(1)=0 .
$$

Because $\pi_{r}(\theta)$ is continuous and decreasing on interval $(\hat{\theta}, 1)$ by the Intermediate Value Theorem, there exists $\bar{\theta} \in(\hat{\theta}, 1)$, such that $\pi_{r}(\bar{\theta})=\pi_{r}(\hat{\theta}-\epsilon)$. Therefore, $\pi_{r}(\theta)>\left(1-c_{r}\right)^{2} / 16, \forall \theta \in(\hat{\theta}, \bar{\theta})$. 


\section{Appendix 4. Proof of Theorem 9 (Oligopolistic Retailers)}

Using the same demand functions in Equations (4) and (5), we obtain the profit function of retailer $i$ in terms of the retailers' quantity choices $Q_{i}, i=1, \ldots, n$ as follows:

$$
\begin{aligned}
\pi_{i}(w, & \left.p_{d}, Q_{i}, Q_{-i}\right) \\
& = \begin{cases}{\left[(1-\theta)\left(1-Q_{i}-Q_{-i}\right)+p_{d}-w\right] Q_{i}} & \text { if } \sum_{i=1}^{n} Q_{i} \geq 1-\frac{p_{d}}{\theta}, \\
\left(1-Q_{i}-Q_{-i}-w\right) Q_{i} & \text { otherwise. }\end{cases}
\end{aligned}
$$

Lemma. Given $w, p_{d}$, and correct beliefs about retailer i's quantity choice, each retailer $i$ chooses $Q_{i}^{*}$ to maximize its profit:

$$
Q_{i}^{*}= \begin{cases}\frac{1-\theta+p_{d}-w}{(n+1)(1-\theta)} & \text { if }\left(p_{d}, w\right) \in \Psi_{1}, \\ \frac{\theta-p_{d}}{n \theta} & \text { if }\left(p_{d}, w\right) \in \Psi_{2}, \\ \frac{1-w}{n+1} & \text { if }\left(p_{d}, w\right) \in \Psi_{3} .\end{cases}
$$

The corresponding retail price is

$$
p_{r}= \begin{cases}\frac{1-\theta+n w+p_{d}}{n+1} & \text { if }\left(p_{d}, w\right) \in \Psi_{1}, \\ \frac{p_{d}}{\theta} & \text { if }\left(p_{d}, w\right) \in \Psi_{2}, \\ \frac{1+n w}{n+1} & \text { if }\left(p_{d}, w\right) \in \Psi_{3},\end{cases}
$$

where

$$
\begin{aligned}
& \Psi_{1}=\Phi \cap\left\{\left(p_{d}, w\right) \mid n \frac{1-\theta+p_{d}-w}{(n+1)(1-\theta)} \geq 1-\frac{p_{d}}{\theta}\right\}, \\
& \Psi_{2}=\Phi \cap\left\{\left(p_{d}, w\right) \mid n \frac{1-\theta+p_{d}-w}{(n+1)(1-\theta)} \leq 1-\frac{p_{d}}{\theta}, n \frac{1-w}{n+1} \geq 1-\frac{p_{d}}{\theta}\right\}, \\
& \Psi_{3}=\Phi \cap\left\{\left(p_{d}, w\right) \mid n \frac{1-w}{n+1} \leq 1-\frac{p_{d}}{\theta}\right\} .
\end{aligned}
$$

Note that $\Phi=\left\{\left(p_{d}, w\right) \mid w \leq p_{d} ; w, p_{d} \in \mathfrak{R}^{+}\right\}$.

Proof. The strategy for retailer $i$ is a quantity choice $Q_{i}$ such that

$\pi_{i}\left(w, p_{d}, Q_{i}^{*}, Q_{-i}^{*}\right) \geq \pi_{i}\left(w, p_{d}, Q_{i}, Q_{-i}^{*}\right), \quad \forall Q_{i}, i=1, \ldots, n$.

If $\left(p_{d}, w\right) \in \Psi_{1}$, then

$$
\pi_{i}\left(Q_{i}\right)=\left((1-\theta)\left(1-Q_{i}-Q_{-i}\right)+p_{d}-w\right) Q_{i} .
$$

First-order conditions yield

$$
Q_{i}=\frac{1-Q_{-i}}{2}+\frac{p_{d}-w}{2(1-\theta)} .
$$

Because all retailers are identical, we can replace $Q_{-i}$ with $(n-1) Q_{i}$, and it follows that

$$
Q_{i}=\frac{1-(n-1) Q_{i}}{2}+\frac{p_{d}-w}{2(1-\theta)} \quad \Leftrightarrow \quad Q_{i}=\frac{1-\theta+p_{d}-w}{(n+1)(1-\theta)} .
$$

Substituting the above into the demand function from the top line of Equation (4),

$$
\sum_{i=1}^{n} Q_{i}=1-\frac{p_{r}-p_{d}}{1-\theta}
$$

and it follows that

$$
p_{r}=\frac{1-\theta+n w+p_{d}}{n+1}
$$

For the cases when $\left(p_{d}, w\right) \in \Psi_{2}$ and $\left(p_{d}, w\right) \in \Psi_{3}$, the proof can be done in a similar manner.

Given the lemma regarding the retailers' best reaction function, the manufacturer's problem is to maximize its profit by choosing $w$ and $p_{d}$ :

$$
\begin{aligned}
\underset{p_{d}, w}{\operatorname{maximize}} & \pi_{m}=\left(w-c_{r}\right) \sum_{i=1}^{n} Q_{i}^{*}+\left(p_{d}-c_{d}\right) Q_{d} \\
\text { s.t. } & Q_{d}= \begin{cases}\frac{\theta p_{r}-p_{d}}{\theta(1-\theta)} & \text { if } \frac{p_{d}}{\theta} \leq p_{r}, \\
0 & \text { otherwise, }\end{cases}
\end{aligned}
$$

(A13) and (A14).

Following the same logic found in Appendix 1 and Appendix 2, we can obtain the equilibrium prices.

\section{References}

Balasubramanian, S. 1998. Mail versus mall: A strategic analysis of competition between direct marketers and conventional retailers. Marketing Sci. 17(3) 181-195.

Caves, R. E., W. F. Murphy III. 1976. Franchising: Firms, markets, and intangible assets. Southern J. Econom. 42 572-586.

Chu, W., E. Gerstner, J. Hess. 1998. Dissatisfaction management with opportunistic consumers. J. Service Res. 1(2) 140-155.

Cohen, A. 2000. When channel conflict is good. Sales and Marketing Management 152(4) 13.

Collett, S. 1999. Channel conflicts push Levi to halt Web sales. Computerworld 33(45) 8.

Coughlan, A., L. Stern, A. El-Ansary. 1996. Marketing Channels, 5th ed. Prentice-Hall, Englewood Cliffs, NJ.

Desiraju, R., S. Moorthy. 1997. Managing a distribution channel under asymmetric information with performance requirements. Management Sci. 43(12) 1628-1644.

Dutta, B., Bergen, M., J. Heide, G. John. 1995. Understanding dual distribution: The case of reps and house accounts. J. Law, Econom. and Organ. 11(1) 189-204.

Gallini, N. T., N. Lutz. 1992. Dual distribution and royalty fees in franchising. J. Law, Econom. Organ. 8(3) 471-501.

Gerstner, E., J. Hess. 1995. Pull promotions and channel coordination. Marketing Sci. 14(1) 43-60. 
CHIANG, CHHAJED, AND HESS

Strategic Analysis of Dual-Channel Supply Chain Design

Harris, J. C. 1976. The Complete Tales of Uncle Remus. Houghton Mifflin, Boston, MA.

Hess, J., E. Gerstner, W. Chu. 1996. Controlling product returns in direct marketing. Marketing Lett. 7(4) 307-317.

Ingene, C. A., M. Parry. 1995. Channel coordination when retailers compete. Marketing Sci. 14(4) 360-377.

Jeuland, A. P., S. M. Shugan. 1983. Managing channel profits. Marketing Sci. 2(3) 239-272.

Kacen, J., J. Hess, W. K. Chiang. 2002. Bricks or clicks? Consumer attitudes toward traditional stores and online stores. Working paper, University of Illinois, Champaign, IL.

Keenan, W. J. 1999. E-commerce impacts channel partners. Indust. Week 248(14) 18.

Kreps, D. M., J. A. Scheinkman. 1983. Quantity precommitment and bertrand competition yield cournot outcomes. Bell J. Econom. 14(2) 326-337.

Lal, R. 1990. Improving channel coordination through franchising. Marketing Sci. 9(4) 299-318.

Liang, T., J. Huang. 1998. An empirical study on consumer acceptance of products in electronic markets: A transaction cost model. Decision Support Systems 24 29-43.

McGuire, T. W., R. Staelin. 1983. An industry equilibrium analysis of downstream vertical integration. Marketing Sci. 2(2) 161-191.
1986. Channel efficiency, incentive compatibility, transfer pricing, and market structure: Equilibrium analysis of channel relationships. Res. Marketing 8 181-223.

Minkler, A. 1991. Why firms franchise: A search cost theory. J. Theoret. Institutional Econom. 148 240-259.

Moriarty, R. T., U. Moran. 1990. Managing hybrid marketing systems. Harvard Bus. Rev. 90(6) 146-155.

Nash, J. F. 1950. The bargaining problem. Econometrica 18(2) 155-162.

Rhee, B., S. Park. 1999. Online store as a new direct channel and emerging hybrid channel system. Working paper, Hong Kong University of Science and Technology, Clear Water Bay, Kowloon, Hong Kong.

Rubin, P. H. 1978. The theory of the firm and the structure of the franchise contract. J. Law Econom. 21 223-233.

Shugan, S. M. 1985. Implicit understandings in channels of distribution. Management Sci. 31(4) 435-460.

Spengler, J. 1950. Vertical restraints and antitrust policy. J. Political Econom. 58(4) 347-352.

Tedeschi, B. 2000. Compressed data; big companies go slowly in devising net strategy. New York Times (March 27).

Tsay, A., N. Agrawal. 2001. Channel conflict and coordination: An investigation of supply chain design. Working paper, Santa Clara University, Santa Clara, CA.

Accepted by Dipak Jain; received March, 2001. This paper was with the authors for 2 revisions. 